\title{
EHMTI-0395. Hypnotic relaxation vs amitriptyline for tension-type headache: let the patient choose
}

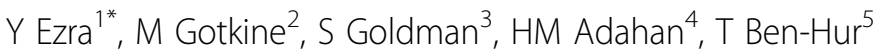 \\ From 4th European Headache and Migraine Trust International Congress: EHMTIC 2014 \\ Copenhagen, Denmark. 18-21 September 2014
}

\section{Introduction}

Although both pharmacological and behavioral interventions may relieve tension-type headache, data are lacking regarding treatment preference, compliance, and feasibility of behavioral intervention in a neurological outpatient clinic setting.

\section{Aims}

To describe patient choice, compliance, and outcome in a neurological clinic where patients are given the choice of the approach they wish to pursue.

\section{Methods}

Patients presenting to the headache clinic with a diagnosis of tension-type headache, were given the choice of amitriptyline (AMT) treatment or hypnotic relaxation (HR), and were treated accordingly. Patients were given the option to cross-over to the other treatment group. HR was performed during standard length neurology clinic appointments by a neurologist. Follow-up interviews were performed between 6 and 12 months following treatment initiation to evaluate compliance, headache frequency or severity, and quality-of-life.

\section{Results}

98 patients were enrolled, 92 agreed to receive prophylactic therapy. 53 (57.6\%) patients chose HR of which 36 (67.9\%)initiated this treatment, 39 (42.4\%) chose AMT of which 25 (64.1\%) initiated therapy. 74\%of the patients in the HR group and $58 \%$ of patients in the AMT group had a $50 \%$ reduction in the frequency of headaches $(P=.16)$. At the end of the study, 26 patients who tried HR compared with 10 who tried AMT continued receiving their initial treatment.

${ }^{1}$ Neurology, Soroka University Medical Center, Beer Sheva, Israel

Full list of author information is available at the end of the article

\section{Conclusions}

HR was a more popular choice among patients. Patients choosing HR reported greater amelioration than those choosing AMT and were found to have greater treatment compliance. HR practiced by a neurologist is feasible in a standard neurological outpatient clinic.

No conflict of interest.

\section{Authors' details}

${ }^{1}$ Neurology, Soroka University Medical Center, Beer Sheva, Israel. ${ }^{2}$ Neurology, Hadassah University Medical Center, Jerusalem, Israel. ${ }^{3}$ Internal medicine, Hadassah University Medical Center, Jerusalem, Israel. ${ }^{4}$ Pain Rehabilitation, Shiba Medical Center, Ramat Gan, Israel. ${ }^{5}$ Neurology, Hadassah University Medical Center, Jerusalem, Israel.

Published: 18 September 2014

doi:10.1186/1129-2377-15-S1-I3

Cite this article as: Ezra et al.: EHMTI-0395. Hypnotic relaxation vs amitriptyline for tension-type headache: let the patient choose. The Journal of Headache and Pain 2014 15(Suppl 1):13.

\section{SpringerOpen ${ }^{\circ}$}

C 2014 Ezra et al; licensee Springer. This is an Open Access article distributed under the terms of the Creative Commons Attribution License (http://creativecommons.org/licenses/by/2.0), which permits unrestricted use, distribution, and reproduction in any medium, provided the original work is properly cited.
Submit your manuscript to a SpringerOpen ${ }^{\circ}$ journal and benefit from:

- Convenient online submission

- Rigorous peer review

- Immediate publication on acceptance

- Open access: articles freely available online

- High visibility within the field

Retaining the copyright to your article

Submit your next manuscript at $>$ springeropen.com 